\title{
Hemodynamic responses during a burpee test adapted in jiu-jitsu practitioners
}

\begin{abstract}
The objective of this study was to identify the behavior of cardiovascular variables: heart rate, blood pressure, double product and compare it with the blood lactate concentration, before and after the adapted 7-minute burpee test. Cross-sectional quantitative study, carried out in a training center in the city of Fortaleza, Ceará, Brazil, from June to July 2019. The sample consisted of 20 male jiu-jitsu athletes, aged between 18 and 50 years. We excluded athletes with musculoskeletal injuries during the test period, who used AAS and practiced another sport. All participants performed the adapted 7-minute burpee test. Before the test, the athletes were at rest to check blood pressure and pre-test lactate. Immediately at the end of the last minute of the test, we measured blood pressure and post-test lactate. Heart rate we checked every minute during the test. The participants had an average age and BMI of $(25.8 \pm 7.96$ years $)$ and $\left(27.05+4.29 \mathrm{~kg} / \mathrm{m}^{2}\right)$, respectively. We identified significant differences in the pre and posttest values for heart rate, blood pressure, double product and lactate $(p<0.05)$. In the correlation of the total number of burpees performed during the test, we identified a statistically significant difference with the body mass index and the double product, but not with the post-test lactate. We conclude that the adapted 7-minute burpee test is an alternative for the evaluation, monitoring and development of cardiovascular fitness of athletes practicing jiu-jitsu.
\end{abstract}

Volume 7 Issue 4 - 2020

\author{
Júlio César Chaves Nunes Filho,' Nicholas \\ Sombra Brito, ${ }^{2}$ Prodamy da Silva Pacheco \\ Neto $^{3}$ \\ 'Master in Medical Sciences, Federal University of Ceará, Brazil \\ ${ }^{2}$ Specialist in Exercise Physiology, Lourenço Filho College, Brazil \\ ${ }^{3}$ Master of Sports Science, University of Trás-os-Montes and \\ Alto Douro, Portugal
}

Correspondence: Júlio César Chaves Nunes Filho, Physical Education Professional, PhD Student in Medical Sciences, Federal University of Ceará, UFC, Brazil, Tel 5585 999683007, Email juliocesref@yahoo.com.br

Received: June 28, 2020 | Published: August 10, 2020

\section{Introduction}

Regular physical activity improves and preserves men's health and quality of life. Sedentary lifestyle is an undesirable condition and poses a health risk. ${ }^{1}$ Jiu-Jitsu is a combat sport that has been growing a lot on the world stage. In recent years, there has been a diverse audience looking for their practice in gyms, fight-training centers, in addition to other establishments where the educational teaching of this sport is promoted. ${ }^{2}$

In Jiu-jitsu training, the athlete or practitioner starts to improve several aspects such as motor coordination and physical fitness, among other diverse abilities through the assimilation of their techniques. ${ }^{3}$ Training capabilities for the development of this martial art include strength, speed, flexibility, endurance, coordination and balance. The combination of these capacities is important for a good performance, as well as for the individual's health. ${ }^{4}$

Having a cardiorespiratory fitness is a sign of a high level of health and quality of life, reduction of diseases and chronic disorders and greater ease to perform daily tasks and physical exercise, as well as recovery. ${ }^{5}$ Bearing in mind that understanding and understanding these changes can be an important factor for the sports performance of practitioners and athletes, as well as for the prevention of cardiovascular diseases, knowing which exercises are more appropriate and at what intensity, can help a better understanding of adaptations of these individuals.

The following exercise is also widely practiced: burpee. If starting from a standing position, fall into an arm position and do a push-up. Then, flex your legs forward with impulse and return to the standing position with a small jump. ${ }^{6}$
The main objective of this work is to show in a quantitative way the monitoring of cardiovascular variations, to identify the behavior of the double product to estimate cardiac effort, as well as to verify the burpee test adapted as an exercise to qualify the cardiovascular effort of jiu-jitsu practitioners.

\section{Materials and methods}

The study was cross-sectional, descriptive, with a quantitative approach. The research period took place from June to July 2019 at a traditional jiu-jitsu academy, located in the city of Fortaleza, Ceará, Brazil. In a universe of 60 athletes, the sample consisted of 20 male jiu-jitsu athletes, between 18 and 50 years old.

The profiles of athletes from all degrees, who had been active in the gym in the last 12 months, with a minimum frequency of three times a week, were included. We excluded from this study athletes with musculoskeletal injuries, those who used anabolic androgenic steroids, and those who practiced another sport. After measuring blood pressure, participants filled out a form with their descriptive data. Participants underwent a body assessment; circumference, height and weight. Through these data it is possible to obtain the BMI of each participant, using the formula height $\mathrm{x}$ weight.

In the pre-intervention moment, the athletes remained at rest for five minutes to check the resting heart rate (HRR) ft40 polar heart monitor, Blood Pressure (BP) PREMIUM sphygmomanometer; PREMIUM stethoscope and Lactate. A qualified health professional performed blood sampling and lactate verification, using a lactimeter plus lactimeter plus gloves and needles.

At the time of the intervention, each participant performed the adapted burpee test. The test consists of a maximum number of 
repetitions of the burpee exercise for 7 minutes. Burpee exercise is one of the most used exercises at HIIT due to its difficulty and recruitment of various muscle groups and elevated heart rate, offering a great contribution to general physical fitness. The exercise became very popular because of the burpee test, which originated in the 1930s and was given this name by the American psychologist Roual H. Burpee. $^{7}$

With the heart rate monitor attached to a chest strap, the individual should perform as many repetitions as possible during the proposed period. Heart rate was checked q every minute of the test. We performed the measurements of heart rate, blood pressure and lactate in the post-intervention moment, immediately after the end of the test. We calculated the double product (SD), which is the product of systolic blood pressure (SBP) by heart rate, before and after the intervention to check the hemodynamic parameters.

The research subjects received information related to research involving human beings in accordance with resolution 466/12 of the code of ethics in research with humans, such as the perspective of protecting the person and his integrity, in order to avoid any risk of injury at the same time, as well as physical, financial and ethical problems. After that, the subjects received and signed the free and informed consent form (ICF).

After collection, we analyzed the data in the program IBM SPSS 22.0 for Windows. To verify the normality and homogeneity of the data, we used the Kolmogorov, Smirnov and Levene tests, respectively. To check the comparison between two variables in the same group at different times, we used the $t$ test for repeated measures. For the comparison of more than three variables, we used
ANOVA. We adopted the Sidak model as an option for the Post-hoc test to verify the post-hoc. We adopted the $95 \%$ confidence interval for all tests, reflecting a value of $\mathrm{p}<0.05$.

\section{Results}

Table 1 presents the descriptive data of the jiu-jitsu practitioners in the present study. The sample consisted of 20 participants with an average age of $25.8 \pm 7.96$ years, weight $80.05 \pm 14.6 \mathrm{~kg}$, height $1.72 \pm 0.06 \mathrm{~m}$ and Body Mass Index (BMI) of $27.05 \pm 4.29 \mathrm{~kg} / \mathrm{m}^{2}$.

Table I Descriptive analysis of the research participants

\begin{tabular}{lll}
\hline & M & SD \\
\hline Age (years) & 25.8 & 7.96 \\
Weight $(\mathrm{kg})$ & 80.05 & 14.09 \\
Height $(\mathrm{m})$ & 1.72 & 0.06 \\
BMI $\left(\mathrm{kg} / \mathrm{m}^{2}\right)$ & 2705 & 4.29 \\
\hline
\end{tabular}

M, mean; BMI, body mass index; SD, standard deviation

Table 2 shows the comparative data in the pre and post intervention moments. Regarding the intervention of the burpee test, differences were identified in the cardiovascular responses before and after the test, such as initial and final systolic blood pressure (SBP) $(\mathrm{p}=0.001)$, initial and final diastolic blood pressure (DBP) $(p=0.001)$, initial and final lactate $(\mathrm{p}=0.001)$ and double final and initial product $(\mathrm{p}=0.001)$.

Table 2 Comparison of blood pressure, lactate and double product values before and after intervention

\begin{tabular}{|c|c|c|c|}
\hline & Pre intervention & Post intervention & $\mathbf{p}$ \\
\hline & $M+S D$ & $M+S D$ & \\
\hline S.B.P. $(\mathrm{mmHg})$ & $|23.85 \pm 8.1|$ & $168.65 \pm 14.62$ & 0.001 \\
\hline D.B.P. $(\mathrm{mmHg})$ & $81.2 \pm 5.8$ & $89.85 \pm 8.13$ & 0.001 \\
\hline Lactate & $4.27 \pm 1.24$ & $15.13 \pm 5.28$ & 0.001 \\
\hline Double product & $9845.35 \pm|788.3|$ & $30105.2 \pm 4116.70$ & 0.001 \\
\hline
\end{tabular}

SBP, systolic blood pressure; DBP, diastolic blood pressure; $M$, mean; SD, standard deviation; $p$, significance value obtained by the t-test for repeated measures, with a $95 \%$ confidence interval $(p<0.05)$

Graph 1 shows the behavior of cardiovascular frequencies observed in situations of rest and exercise. We found significant differences $(p>0.05)$ in the values between each series, when compared to the initial stage of the intervention. It is noticed a peak of elevation of the initial HR, until the measurement of the first minute, soon after, its progression became less accentuated.

There was a significant increase $(\mathrm{p}<0.05)$ in the pre-test HR (FC00) for the other moments of the test (FC01, FC02, FC03, FC04, FC05, FC06 and FC07). Despite the progression of HR during the test and differences found between each minute evaluated, it can be seen that the heart rate in the last test period (FC07) showed a statistically significant difference $(\mathrm{p}>0.05)$, when compared to all other evaluated periods.
We subdivide Figure 1 into three scatter plots of the relationship between the numbers of Burpees performed with: the body mass index (a), double product (b) and the post-proof lactate (c). When related to figure $\mathrm{A}$, he found a negative and statistically significant correlation with values of $\mathrm{r}=-484$, classified as moderate, with the value of $p=0.03$. For this same figure, the value of $\mathrm{r}^{2}=0.235$ was found for simple linear regression. In figure B, a positive correlation was found, statistically significant and classified as very strong $\mathrm{r}=0.954$ with the value of $\mathrm{p}=0.000$ and simple linear regression of $\mathrm{r}^{2}=0.910$.

However, no significant correlation was found between the number of burpees performed vs the post-race lactate $(p=0.329)$. The linear regression value found was $\mathrm{r}^{2}=0.06$ showing a small effect of the influence of the amount of burpees on changes in lactate. 


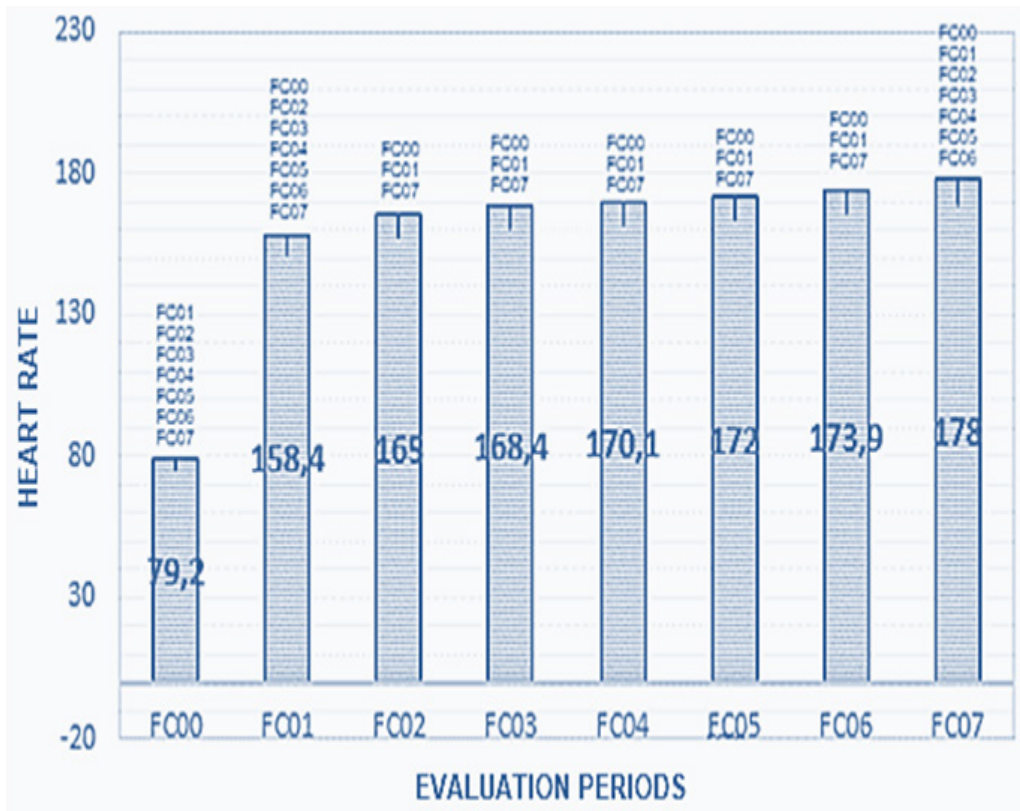

Graph I Comparison of heart rate in repeated measures test.

Legend: comparison of variables through the repeated measurement test, using the $95 \%$ confidence interval. The symbols present in each column represent a statistically significant difference with the variable in the present column $(p<0.05)$.

a)

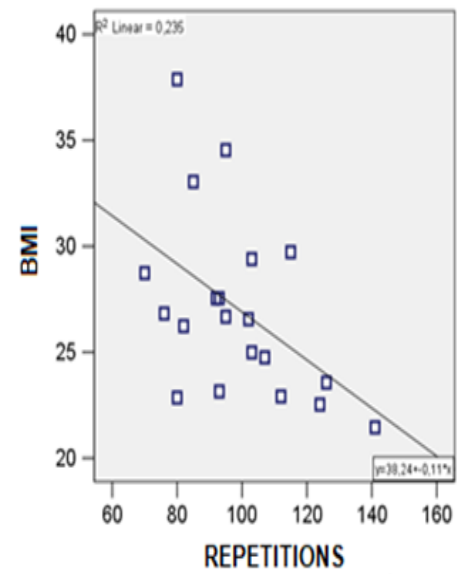

b)

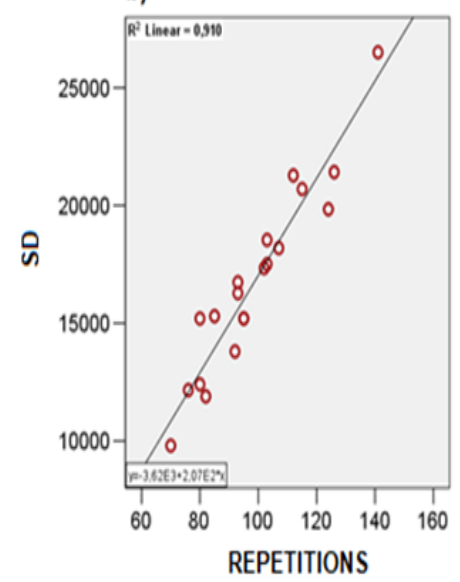

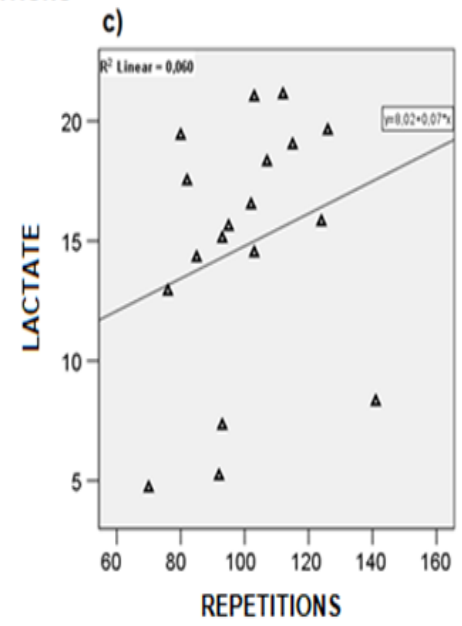

Figure I Relationship between numbers of burpees executed with body mass index, double product and lactate post-test.

BMI, body mass index; DP, double product.Values obtained through Pearson's correlation and simple Linear Regression, with a 95\% confidence interval. 


\section{Discussion}

The present study aimed to verify the dynamic variables of HR, SBP, DBP and double product behavior (DP) in the adapted burpee test and to relate the test to the levels of cardiorespiratory resistance in jiu-jitsu athletes. Burpee is one of the most used exercises at HIIT due to its difficulty and recruitment of several muscle groups, being responsible for the increase in heart rate. ${ }^{5}$

SBP and DBP increased significantly, but we can see a greater peak in SBP. According to ACSM. ${ }^{7}$ SBP and DBP exhibit different behaviors during exercise. In continuous activities of progressive intensity, the SBP increases in direct proportion to the intensity of the exercise, due to the increase in cardiac output. Being an exercise that involves speed and power, the burpee has a large recruitment of motor units, studies such as Prabhakar \& Peng ${ }^{8}$ report that the increase in blood pressure may be influenced by the increase in the number of motor units requested during the exercise.

However, another important data is the HR peak in the last minute. The researchers observed that there is a relationship between the time of exercise between the acute responses of $\mathrm{HR}$ and BP. These increase in proportion to the number of times the same exercise is performed. ${ }^{9}$ In Graph 1, we can see that there was an increase every minute of the HR test; the significant increase was from minute seven compared to FCR. This result corroborates with the study Guimarães et al. ${ }^{5}$ where the burpee test was used as one of the protocols to measure how HIIT should be applied in the daily lives of active people. Where the maximum heart rate increased by $192.23 \pm 5.13 \mathrm{bpm}$.

Other study observed that both HR and SBP tend to be greater in strength exercises that involve smaller loads and many repetitions, as well as in continuous aerobic activities than in larger loads with smaller repetitions. It seems that the overload imposed on the myocardium in localized exercises depends more on the exercise time (number of repetitions) than on the load itself. ${ }^{10}$

A recent research observed similar results in the increase in $\mathrm{HR}$ and lactate according to the test progression. In the mentioned study, the burpee test was performed on a boxing athlete with the same duration as the competition, in the research 35 burpees were performed in a 3-minute round, 3 times, that is, 105 burpees during the entire duration of the test. The drop in yield was proportional to the increase in lactate and HR. ${ }^{11}$

Studies show that physical exercise promotes a decrease in postexercise pressure. Several researchers' studies presents decrease in BP through the practice of aerobic exercises, in addition to other entities such as the Brazilian Society of Cardiology and the American College of Cardiology recommending the performance of predominantly aerobic exercises for hypertensive individuals. However, more recently, there has been an increase in interest in various segments of the population for other types of physical exercise, in which the practice of strength training (ST) stands out.

In jiu-jitsu training you have this aerobic and strength work, the cardiorespiratory system is used a lot to keep pace in combat, and force is used to hold or knock the opponent. There was a significant HR difference during the test, an exponential increase since the beginning of the exercise, as well as during the entire intervention process, also observing an increase in the SBP and DBP during the exercise. This cardiorespiratory increase before and during is related to the test performed (adapted burpee test) knowing that it can be characterized as a high intensity aerobic activity, understanding that the responses during the exercises are part of the same. Bearing in mind, that lactate during exercise also plays a role in the process and its significant increase during the intervention.

Knowledge of the heart rate (HR) response in different exercise situations becomes essential for the correct prescription and subsequent control of aerobic training loads. ${ }^{12}$ The maximum heart rate (HRM) is the highest HR value during a maximum effort until exhaustion, and used as one of the criteria for checking the maximum effort in progressive exercise tests. ${ }^{13}$ Because it has a close relationship with oxygen consumption, HR is used as a basis for prescribing exercise intensity in aerobic training programs. ${ }^{14}$

In the practice of jiu-jitsu, the HR levels can reach their maximum through the effort of the participants, as it is required that they have the highest oxygen consumption during the fight. The adapted burpee test came as close as possible to this reality that athletes go through on a training or competition day.

The lactate level increases as the athlete struggles and imposes to have a motor explosion from the ground, generating accumulation by muscular effort. This accumulation causes the muscle to lose its potential for explosion causing the athlete to slow down. Exercises performed with greater intensity result in a higher lactate production. ${ }^{15}$

Table 2 shows an increase in lactate from $4.27 \pm 1.24$ to $15.13 \pm 5.28$. Corroborating a study by Pereira et al. ${ }^{16}$ who collected lactate from seven jiu-jitsu athletes after a 7-minute fight and observed a reduction in blood lactate. They also saw a significant increase from 4.0 to $14.2 \pm 5.9$ after the fight, really illustrating a large participation of the glycolytic pathway during the practice of the sport.

The double-product is the best non-invasive method to assess myocardial work, during rest or continuous physical efforts of an aerobic nature, as it has a strong correlation with myocardial oxygen consumption. ${ }^{17}$ In the study by Polito et al. ${ }^{18}$ the double product variable was observed after a unilateral knee extension exercise session, where the variation was observed after two groups performed a session of 4 series G1 with an interval of 1 minute and G2 twominute break. The most significant response was in the G1 group, in which the double product was (SD) $9870.3 \pm 2250.3$ and in the four series of the exercise reaching $20893.4 \pm 6215.6$. In the present study, the greatest increase in the double product, started from the initial value of $9845.35 \pm 1788.31$, reaching $30105.2 \pm 4116.70$ right after the end of the exercise in minute seven. This higher percentage in the result may be due to the burp test, which is an exercise that uses the body as a whole, and there is no interval in the test.

The importance of understanding these changes can be an essential factor for cardiovascular prophylaxis and athletes' sports performance, factors such as type of exercise, intensity and duration are important for a better understanding of adaptations. ${ }^{18}$

As a possible limitation, the present study points to a limited sample that may reflect in a smaller representation of the studies presented in this research. The variability between the ages of the practitioners can also influence the context of the research, since age can modify the cardiorespiratory resistance of the practitioner. ${ }^{19}$

\section{Conclusion}

In conclusion, the results of the present study showed significant differences in all studied parameters: heart rate, systolic and diastolic blood pressure, lactate, and in the double product. It showed changes when compared to the initial and final values, with variability in cardiorespiratory resistance. 
The results found allow the different coaches and physical education professionals to use the adapted burpee test as an assessment in jiu-jitsu athletes, to monitor the development of cardiorespiratory fitness and general physical fitness.

\section{Acknowledgments}

None.

\section{Conflicts of interest}

The authors declare there are no conflicts of interest.

\section{Funding}

None.

\section{References}

1. Carvalho TD, Nóbrega AD, Lazzoli JK, et al. Official position of the Brazilian Society of Sports Medicine: physical activity and health. Rev Bras Med Sport. 1996;2(4):79-81.

2. Ferreira, DAC. Ferreira, APU, Bezerra, JAX, et al. Physical and psychological benefits acquired by practitioners of jiu-jitsu. Health Dialogues. 2019;1(2).

3. Rufino LGB, Martins CJ. Brazilian Jiu Jitsu in extension. Science in Extension Journal. 2011;7(2):84-101.

4. Silva Neto A. Effect of specific anaerobic resistance training for jiujitsu athletes in relation to handgrip strength and muscle power. Hórus. 2017;5(2):188-209.

5. Guimarães VF, de Almeida PHF, Maresana RF. Physiological, affective and perceptual aspects of protocols adapted for a HIIT program with women. Rbpfex. 2018;12(75):462-470.

6. Podstawski R, Kasietczuk B, Boraczyński T, et al. Relationship Between BMI and Endurance- Strength Abilities Assessed by the 3 Minute Burpee Test. International Journal of Sports Science. 2013;1(3):28-35.

7. Sawka MN., Burke, LM, Eichner ER, et al. American College of Sports Medicine position stand. Exercise and fluid replacement. Med Sci Sports Exerc. 2007;39(2):377-390.
8. Peng Y, Prabhakar NR. Effect of two paradigms of chronic intermittent hypoxia on carotid body sensory activity. J Appl Physiol. 2004;96(3):12361242.

9. Gotshal R, Gootman J, Byrnes W, et al. Noninvasive characterization of the blood pressure response to the double-leg press exercise. Journal for Exercise Physiologists. 1999;2(4).

10. Farinatti PTV, Assis BFCB. Study of heart rate, blood pressure and double-product in exercises against resistance and continuous aerobic. RBAFS. 2000;(5):5-16

11. Siska L, Brodani J. Use of Burpees in Combat Sports Conditioning Training-A Pilot Study. IJSPE. 2017;3(4):1-6.

12. Bezerra De Almeida M. Heart rate and exercise: An evidence based interpretation. Brazilian Journal of Kinanthropometry and Human Performance. 2007;9(2):196-202.

13. Denadai BS, Ortiz MJ, Greco CC, et al. Interval training at $95 \%$ and $100 \%$ of the velocity at VO2 max: effects on aerobic physiological indexes and running performance. Appl Physiol Nutr Metab. 2006;31(6):737-743.

14. Tanaka H, Monahan KD, Seals DR. Age-predicted maximal heart rate revisited. J Am Coll Cardiol. 2001;37(1):153-156.

15. Maughan R, Gleeson M, Greenhaff PL. Biochemistry of exercise and training. Manole. 2000.

16. Pereira RF, Lopes CR, Dechechi JC, et al. Lactate removal kinetics on brazilian jiu-jitsu athletes. Brazilian Journal of Prescription and Exercise Physiology. 2011;5(25):39-44.

17. GobelFL, Norstrom LA, Nelson RR, et al. The rate-pressure product as an index of myocardial oxygen consumption during exercise in patients with angina pectoris. Circulation. 197857(3):549-556.

18. Polito MD, Simao R, Nóbrega ACL, et al. Blood pressure, heart rate, and rate-pressure product in successive resistance training sets with different rest intervals. Rev Port Cienc Desp. 2004;4(3):7-15.

19. Levine BD, Baggish AL, Kovacs RJ, et al. Eligibility and disqualification recommendations for competitive athletes with cardiovascular abnormalities: task force 1: classification of sports: dynamic, static, and impact: a scientific statement from the American Heart Association and American College of Cardiology. J Am Coll Cardiol. 2015;66(21):2350 2355 